Open Access

\title{
Mesozooplankton biomass and copepod estimated production in a temperate estuary (Mondego estuary): effects of processes operating at different timescales
}

Dina Amanda Gonçalves ${ }^{1}$, Sónia Cotrim Marques ${ }^{1 *}$, Ana Lígia Primo, Filipe Martinho", Maria Donas-Bôtto Bordalo² and Miguel Ângelo Pardal'

\begin{abstract}
Background: A fundamental step in characterizing marine planktonic communities is the knowledge of the variability of their biomass and production, in order to assess the flux of matter through the food web and estimate the fate of this energy. The zooplankton assemblage's dynamics of the Mondego estuary (Portugal) have been extensively characterized, but none have focused on biomass and secondary production. In the present study, zooplankton biomass and secondary production were investigated with a seasonal basis in a fixed station, located at the mouth of the Mondego estuary (Portugal), with emphasis on the copepod community. In order to study the influence of physical processes operating at different temporal scales, sub-surface and near-bottom samples were collected every $2 \mathrm{~h}$ in diel and tidal cycles, over neap tides.

Results: Copepods dominated the biomass during spring $\left(0.585 \pm 0.671 \mathrm{mg} \mathrm{C} \mathrm{m}^{-3}\right)$, summer $\left(0.287 \pm 0.383 \mathrm{mg} \mathrm{C} \mathrm{m}^{-3}\right)$, and winter $\left(0.221 \pm 0.128 \mathrm{mg} \mathrm{C} \mathrm{m}^{-3}\right)$. Lower observed biomass values were probably due to the higher mesh size used in comparison to previous studies in other estuarine systems. No differences were detected between seasons in total zooplankton biomass. Concerning diel cycle, significant variation occurred mainly in spring and winter, with substantially higher biomass values being registered at night for both the surface and bottom. Moreover, copepod biomass was consistently higher at the bottom during winter. In this season, bottom samples presented higher copepod biomass both at ebb and flood tides. From the GLM analyses run for each season, chlorophyll a, diel phase, and depth were significant factors.

Conclusions: The considerable complexity in the processes structuring the dynamics and composition of biomass and production rates has been shown. Our results demonstrated that along spring and winter, secondary production varied according to diel phase and depth. In winter, night and bottom samples revealed consistently higher daily secondary production rates. From this, it is possible to conclude that local factors (river flow, predation, food limitation) regulate the seasonal variations in zooplankton biomass and production in the Mondego estuary.
\end{abstract}

Keywords: Mondego estuary; Estuarine copepods; Biomass and secondary production; Seasonal and diel variations

\footnotetext{
* Correspondence: scotrim@ci.uc.pt

'Department of Life Sciences, Centre for Functional Ecology_CFE, University

of Coimbra, Calçada Martins de Freitas, Coimbra 3000-456, Portugal

Full list of author information is available at the end of the article
}

\section{$\underline{\underline{\theta}}$

(c) 2015 Gonçalves et al. Open Access This article is distributed under the terms of the Creative Commons Attribution 4.0 International License (http://creativecommons.org/licenses/by/4.0/), which permits unrestricted use, distribution, and reproduction in any medium, provided you give appropriate credit to the original author(s) and the source, provide a link to the Creative Commons license, and indicate if changes were made. 


\section{Background}

The dynamic nature of estuarine ecosystems is defined by varying physical and chemical characteristics, including fluctuations in salinity, temperature, turbidity, and oxygen in the water column (Elliott and McLusky 2002). Water circulation and land influence also induce high variability on the distribution and structure of planktonic populations, which tend to be spatially and temporally heterogeneous when compared to other aquatic systems (Marques et al. 2007). Although these habitats are considered stressful and harsh, few organisms are able to survive and adapt to these conditions and manage to escape from competition in the sea or surrounding freshwater, and often thrive in large numbers. In fact, all estuaries show a gradual reduction in diversity but not in abundance or productivity of species when compared to adjacent aquatic habitats (Elliott and McLusky 2002).

Due to their significant abundance and biomass in estuarine and nearshore areas, zooplankton play a key role as major grazers in aquatic food webs, being critical intermediaries in the flow of energy and matter through marine food chains, from primary producers to consumers at higher trophic levels, such as fish, marine mammals, and turtles (Leandro et al. 2014, Richardson 2008). The composition and abundance of estuarine zooplankton are distinct and display a non-homogeneous, variable spatial distribution (Ré et al. 2005). Zooplankton distribution is influenced by factors acting on many scales, with multiple interactions in an unstable aquatic environment. For instance, estuaries are strong advective environments as a direct consequence of the tidal currents (ebb and flood) and river flow, imposing an additional stress factor for zooplankton populations (McLusky and Elliott 2004). Moreover, zooplankton exhibit a variety of daily cycles including vertical and horizontal migrations, changes in feeding behavior, and alternative reproductive states (Hays 2003). This suggests that there is an important link between hydrological cycles and zooplankton community ecology in these habitats. In most estuarine ecosystems, copepods comprise the bulk of the holoplankton (Day et al. 1989), even outnumbering insects by possibly three orders of magnitude. The relevance of copepods is such that the reproductive and recruitment success of several pelagic fish and shellfish species of high economic value are extremely dependent on the dynamics of their populations (Beaugrand et al. 2003, Conover et al. 1995). The copepod community of the Mondego estuary is dominated by the Acartia genus (Azeiteiro et al. 1999, Vieira et al. 2003). These organisms reproduce throughout the year, and several annual growth generations can be found in temperate systems like this one because of favorable temperatures and high food availability (Kleppel 1992, Leandro et al. 2007).
Productivity has become a central and extensively studied aspect in marine plankton research over the last few decades (Runge and Roff 2000). It is of interest as a measure of energy flow through a population and as an indicator of its physiological or nutritional state (Kimmerer 1987). The zooplankton communities of the Mondego estuary have been extensively characterized and studied on various levels by a number of researchers (e.g., Marques et al. 2006, 2014, Primo et al. 2009, Vieira et al. 2003), but none have focused on the exchange of biomass and secondary production with the estuary and coastal waters.

In order to better comprehend the role of zooplankton in the material flow of this ecosystem, the principle aims of this study were as follows: (1) to quantify zooplankton biomass categorized by taxonomic groups; (2) to estimate copepod production by using the global model of Huntley and Lopez (1992); (3) to evaluate the effect of processes operating at different timescales on biomass transport at the interface between the estuary and the adjacent coast: seasons, tidal, and diel cycles.

\section{Methods \\ Study site}

The Mondego estuary is located on the Atlantic west coast of Portugal $\left(40^{\circ} 08^{\prime} \mathrm{N}, 8^{\circ} 50^{\prime} \mathrm{W}\right)$ and has a warm temperate climate. With an area of about $8.6 \mathrm{~km}^{2}$, it comprises two arms (north and south) that are separated by a central island (Fig. 1). The two arms have different hydrographic characteristics, being the north arm deeper ( 5 to $10 \mathrm{~m}$ during high tide, tidal range of 1 to $3 \mathrm{~m}$ ) and presenting lower residence times ( $<1$ day). The southern arm is almost silted up in upstream areas ( 2 to $4 \mathrm{~m}$ during high tide, tidal range of 1 to $3 \mathrm{~m}$ ), causing freshwater to flow mainly through the north arm. Water circulation in this arm is mostly due to the tides and a small input of freshwater from a connecting tributary. Due to the differences in depth, tide penetration is faster in the north arm and causes greater daily changes in salinity, whereas temperature shows more daily variations in the south arm (Marques et al. 2002).

\section{Field sampling and laboratory procedures}

Zooplankton samples were collected at a fixed station located at the mouth of the Mondego estuary (Fig. 1), from the summer of 2005 to the spring of 2006. The sampling station was characterized by depths of 6 to $13 \mathrm{~m}$. In this area, there is a strong influence of both river and coastal waters. Seasonal sampling took place in June, October, and December of 2005 and in March of 2006, during neap tides. Collection was performed every $2 \mathrm{~h}$ over diel cycles, with one sample being gathered from each of two depth ranges: sub-surface and $1 \mathrm{~m}$ above the bottom. Concerning the bottom samples, the net was attached to a winch cable and a weight was 


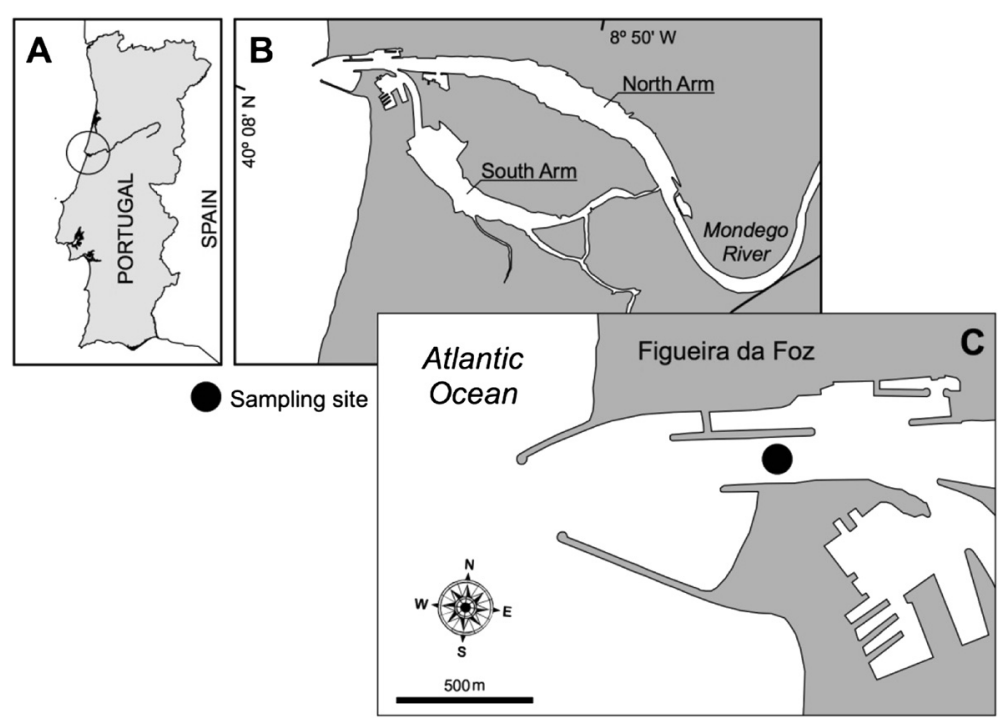

Fig. 1 Location of the Mondego estuary on the Portuguese coast (a), the Mondego estuary (b) and sampling site within the estuary (c)

added to the lower end of the rope. A bridle was adjusted so that the frame of the net (not the mesh netting) supported the weight. The zooplankton net was then lowered very slowly and carefully to the desired depth and dragged for $3 \mathrm{~min}$. The net was raised out of the water in one motion until the plankton bucket was just above the surface. Samples were classified as day or night, with the day phase being taken from sunrise to sunset and the night phase from the corresponding period. Zooplankton was gathered by horizontal tows at low speed, using a bongo net of $335 \mu \mathrm{m}$ mesh size ( $0.5 \mathrm{~m}$ diameter) equipped with a Hydro-Bios flowmeter to calculate the filtered volume (average $20 \mathrm{~m}^{3} \pm$ $10.3 \mathrm{~m}^{3}$ ). Samples were fixed and preserved in a $5 \%$ borax-buffered formaldehyde seawater solution. In parallel with the tows, water temperature $(\mathrm{T})$ and salinity $(\mathrm{S})$ were recorded at each collection point using a WTW Cond 330i meter at both depths. Water samples of $500 \mathrm{ml}$ were also filtered for determination of chlorophyll a (Chl a) and suspended particulate matter (SPM). The bottom water samples were obtained with a Van Dorn sampler. For determination of Chlorophyll a, $500-1000 \mathrm{ml}$ water samples were filtered onto Whatman GF/C glass-fiber filters followed by extraction following the protocol of Parsons et al. (Parsons et al. 1985). SPM was estimated by filtering $700 \mathrm{ml}$ water through pre-combusted and pre-weighted Whatman GF/C filters and dried at $60{ }^{\circ} \mathrm{C}$ for $72 \mathrm{~h}$ and combusted at $450{ }^{\circ} \mathrm{C}$ for $8 \mathrm{~h}$ (APHA 1995).

\section{Biomass determination}

Organisms were separated by taxonomic group into small previously weighed aluminum capsules under Leica M80 stereomicroscopes. Samples with very high numbers of individuals were sub-sampled as necessary by using a Folsom plankton splitter. Subsequently, the capsules were placed in heat resistant acrylic multiwell trays and put in a drying oven set to $60^{\circ} \mathrm{C}$ for at least $24 \mathrm{~h}$, as recommended (Lovegrove 1962, 1966). This procedure assured water removal without affecting organic content (Ré et al. 2005). Zooplankton biomass was expressed as $\mathrm{mg} \mathrm{m}^{-3}$. Dry weight were converted according to carbon weight $(\mu \mathrm{g} C)$ assuming that it corresponded to $40 \%$ of the dry weight, according to the methods employed by Omori and Ikeda (1984) and Båmstedt (1986). These values represent a realistic estimate of biomass and the nutritive value of zooplankton (Ré et al. 2005).

\section{Estimation of copepod production}

Daily secondary production rate was determined with the following equation:

$$
P=B g,
$$

where $P$ is the production ( $\mathrm{mg} \mathrm{C} \mathrm{m}^{-3} \mathrm{~d}^{-1}$ ), $B$ is the copepod biomass $\left(\mathrm{mg} \mathrm{C} \mathrm{m}^{-3}\right)$, and $g$ is the weight-specific growth rate $\left(\mathrm{d}^{-1}\right)$. Estimates of copepod growth rates were obtained from the temperature-dependent predictive method of Huntley and Lopez (1992) with the expression:

$$
g=0.0445 e^{0.111 T}
$$

being $T$ equal to temperature $\left({ }^{\circ} \mathrm{C}\right)$. These authors have shown that for marine copepods, the temperature dependence of growth rates surpasses species differences. As a result, the exponential growth model presented should be applicable to production estimates of the entire communities, regardless of species composition or 
size frequency. In this study, growth was directly estimated from the weight of adult organisms for each taxonomic group and recorded temperatures.

\section{Statistical analysis}

Permutational univariate analysis of variance (PERMANOVA, Anderson et al. 2008) was used to test for significant differences in both environmental and biological variables. Tests were applied to non-transformed data, and based on Euclidian distances between samples, considering all the factors as fixed and with unrestricted permutation of raw data.

Environmental variables were tested with a two-way design (season/depth) and seasonal variations in zooplankton biomass by a one-way design (season). Copepod vertical distribution of biomass and production were tested for each season separately by two-way design (diel/ depth and tide/depth). PERMANOVA tests were applied with PERMANOVA + for PRIMER software (PRIMER v6 and PERMANOVA + v1, PRIMER-E Ltd.). To identify which environmental variables influenced copepod production, Generalized Linear Models (R software; R Development Core Team 2008) were applied. Again, each season was analyzed separately and environmental variables included were the following: salinity, temperature, chlorophyll a, and suspended particulate matter. Tide, diel cycle, and depth were included as nominal variables, as well as interaction tide: depth and diel cycle: depth. Significant results in interaction terms indicate that the relationships between the explanatory variables are not the same for each condition. Variables were transformed whenever necessary (presence of extreme values): log transformation of Chl a and SPM in summer, winter, and spring and square root transformation of secondary production in spring. The Spearman correlation coefficient was used to test for collinearity between continuous variables, and variables were excluded whenever the values were superior to 0.7. A Gaussian error distribution was used for the response variables (copepod production). The selected variables included in the final model were obtained using an automatic stepwise selection (drop 1), and the Akaike information criterion (Akaike 1974) was used to select the best model.

\section{Results}

\section{Environmental characterization}

The hydrological conditions recorded during the study period are shown in Fig. 2. A clear seasonal pattern of precipitation and runoff was observed, with the highest values in winter. However, in the hydrological year of 2005/2006, high values were also observed in March and April.

Salinity and water temperature revealed a marked seasonal variation typical of temperate estuaries (Fig. 3). Salinity ranged between 31.4-35.2 in summer and 6.733.0 in autumn. Water temperature varied from 18.6$20.1^{\circ} \mathrm{C}$ in spring and $11.3-13.1^{\circ} \mathrm{C}$ in autumn. There were significant differences in the water temperature values between all seasons (pseudo- $\mathrm{F}=293.90, p<0.05$ ), while salinity displayed considerably higher values in spring and summer (pseudo- $\mathrm{F}=31.86, p<0.05$ ). A similar pattern of variation was found for SPM, which presented significantly higher values in warmer seasons $(0.044 \pm$ $0.025 \mathrm{mg} \mathrm{m}^{-3}$ spring, $0.033 \pm 0.017 \mathrm{mg} \mathrm{m}^{-3}$ summer, pseudo- $\mathrm{F}=25.01, p<0.05)$. Chlorophyll a concentration increased noticeably in spring $\left(4.8 \pm 3.3 \mathrm{mg} \mathrm{m}^{-3}\right)$ and autumn $\left(4.6 \pm 2.7 \mathrm{mg} \mathrm{m}^{-3}\right)$ (pseudo- $\mathrm{F}=9.41, p<0.05$ ).

A vertical variation of environmental parameters in the water column was also detected (Fig. 3). Mean salinity values were generally higher at the bottom during summer and autumn (post hoc $t$ test, $p<0.05$ ), showing no differences for the remaining seasons. At the surface, a sharp decrease in salinity was noted in autumn (6.7 \pm 3.8 ), indicating the occurrence of freshwater intrusion. Concerning temperature, autumn presented significantly higher values for the bottom, while values increased at

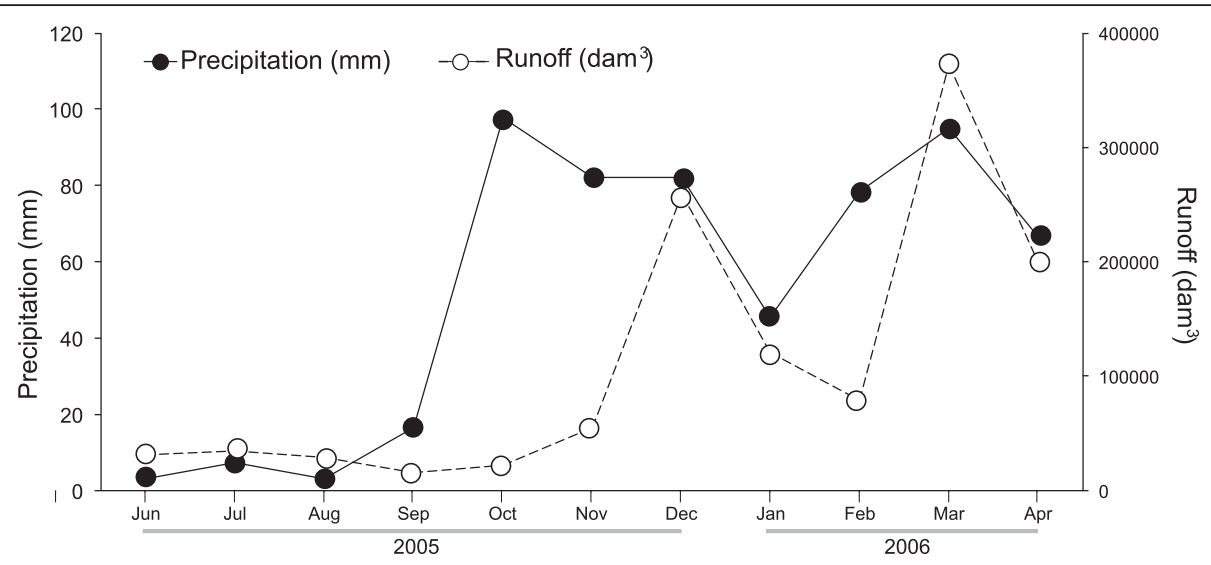

Fig. 2 Monthly variation of precipitation (mm) and river runoff $\left(\mathrm{dam}^{3}\right)$ from June 2005 to April 2006 

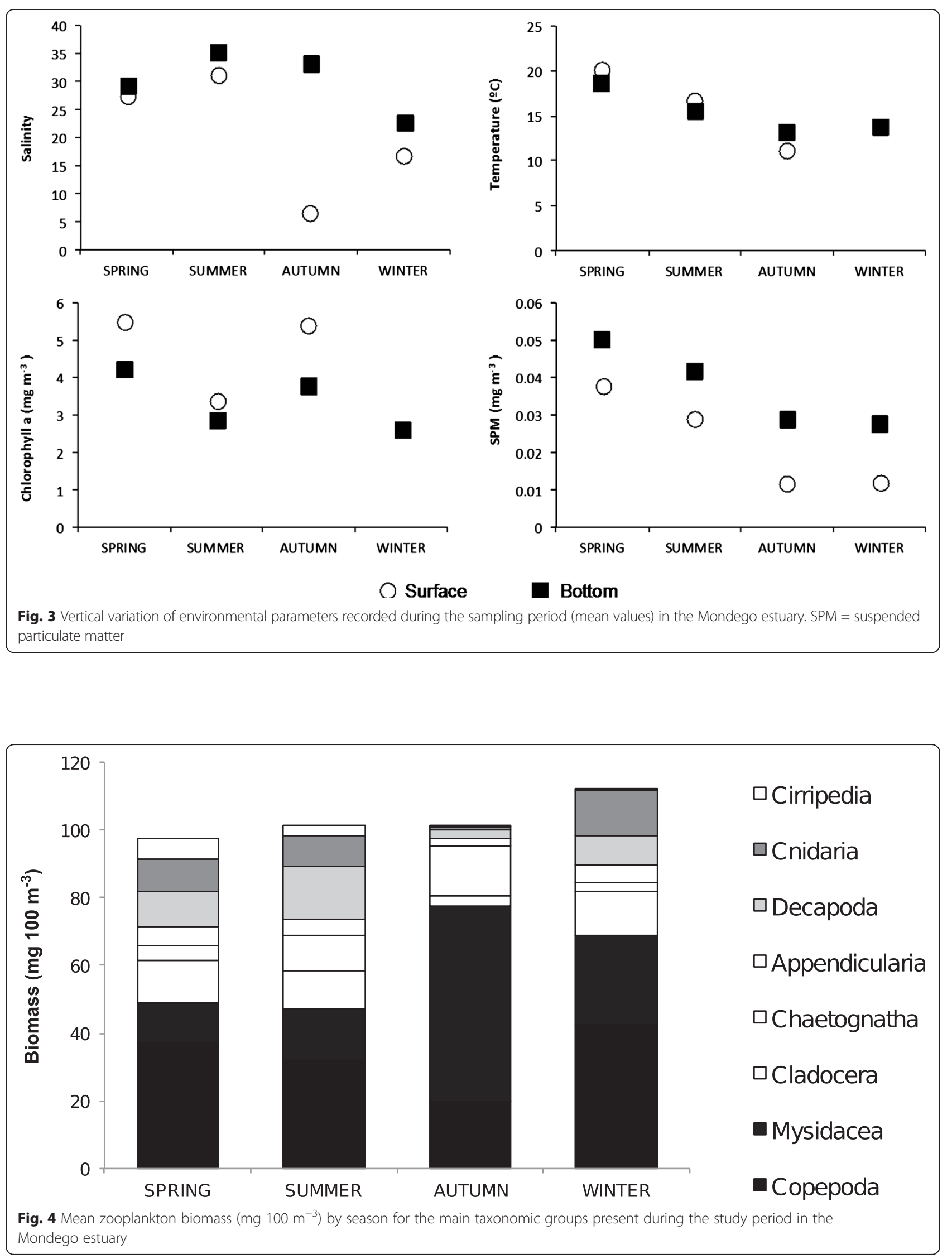
the surface during spring (post hoc $t$ test, $p<0.05$ ). Chlorophyll a concentration was always higher at the surface (pseudo-F $=4.85, p<0.05$ ) in opposition to the SPM load, which had higher values at the bottom (pseudo-F $=32.69, p<0.05$ ).

\section{Seasonal, diel, and tidal variations of biomass and secondary production}

Zooplankton organisms were identified in a total of eight taxonomic groups (Fig. 4). Copepoda, Mysidacea, and Cladocera were the main taxa collected, contributing to $69 \%$ of the total biomass. Copepods dominated biomass during spring $\left(37.4 \pm 75.71 \mathrm{mg} 100 \mathrm{~m}^{-3}\right)$, summer $(32.1 \pm$ $\left.29.8 \mathrm{mg} 100 \mathrm{~m}^{-3}\right)$, and winter $\left(42.2 \pm 52.72 \mathrm{mg} 100 \mathrm{~m}^{-3}\right)$, while Mysidacea was the main contributor in autumn.

For total zooplankton biomass, no differences were observed between seasons. Nevertheless, Chaetognatha had significantly higher values in summer and autumn (pseudo$\mathrm{F}=3.55, p<0.05$ ), Mysidacea in autumn (pseudo- $\mathrm{F}=2.58$, $p<0.05$ ), and Cirripedia in summer and spring (pseudo-F $=9.31, p<0.05$ ) (Fig. 4). In general, copepod biomass was higher in winter, followed by spring, summer, and autumn.

The diel and tidal vertical variations of copepod biomass are shown in Figs. 5 and 6, respectively. Diel variation occurred mainly in spring (pseudo-F $=10.70, p<0.05$ ) and winter (pseudo-F $=8.31, \quad p<0.05$ ), with substantially higher biomass values being registered at night for both the surface and bottom, respectively. Moreover, copepod biomass was consistently higher at the bottom during winter (pseudo-F =6.27, $p<0.05$ ) (Fig. 5).
Regarding tidal phases, no significant differences were observed between flood and ebb tides, even when considering vertical distribution, bottom, and surface values. In winter, bottom samples presented higher copepod biomass, both at ebb and flood tides (pseudo-F $=4.99, p<0.05$ ) (Fig. 6).

Secondary production values for copepods were much lower during autumn $\left(0.04 \pm 0.03 \mathrm{mg} \mathrm{C} \mathrm{m} \mathrm{m}^{-3} \mathrm{~d}^{-1}\right.$, pseudo-F $=2.67, p<0.05$ ) (Fig. 7). Daily secondary production rates exhibited significant differences in spring and winter, for both diel and depth factors. Throughout winter, the highest values were found at night $(0.13 \pm$ $0.12 \mathrm{mg} \mathrm{C} \mathrm{m} \mathrm{d}^{-3}$, pseudo-F $\left.=5.25, p<0.05\right)$ and in the bottom samples $\left(0.13 \pm 0.13 \mathrm{mg} \mathrm{C} \mathrm{m}^{-3} \mathrm{~d}^{-1}\right.$, pseudo- $\mathrm{F}=$ $2.96, p<0.05)$. In spring, diel variation changed according to depth (pseudo-F $=4.68, p<0.05$ ). The surface presented considerably higher values during the night (post hoc $t$ test, $p<0.05$ ), while at the bottom, there were no noteworthy differences. Copepod production showed no variation considering tidal phases.

\section{Relationship between copepod production and environmental factors}

GLM analyses identified, for each season, which environmental factor had higher influence on copepod secondary production variation, resulting in the best model that fits observed values (Table 1, Fig. 7). From the GLM analyses ran for each season, chlorophyll a, diel phase, and depth were significant factors for the models (Table 1, Fig. 7). Spring and winter displayed higher coefficients of
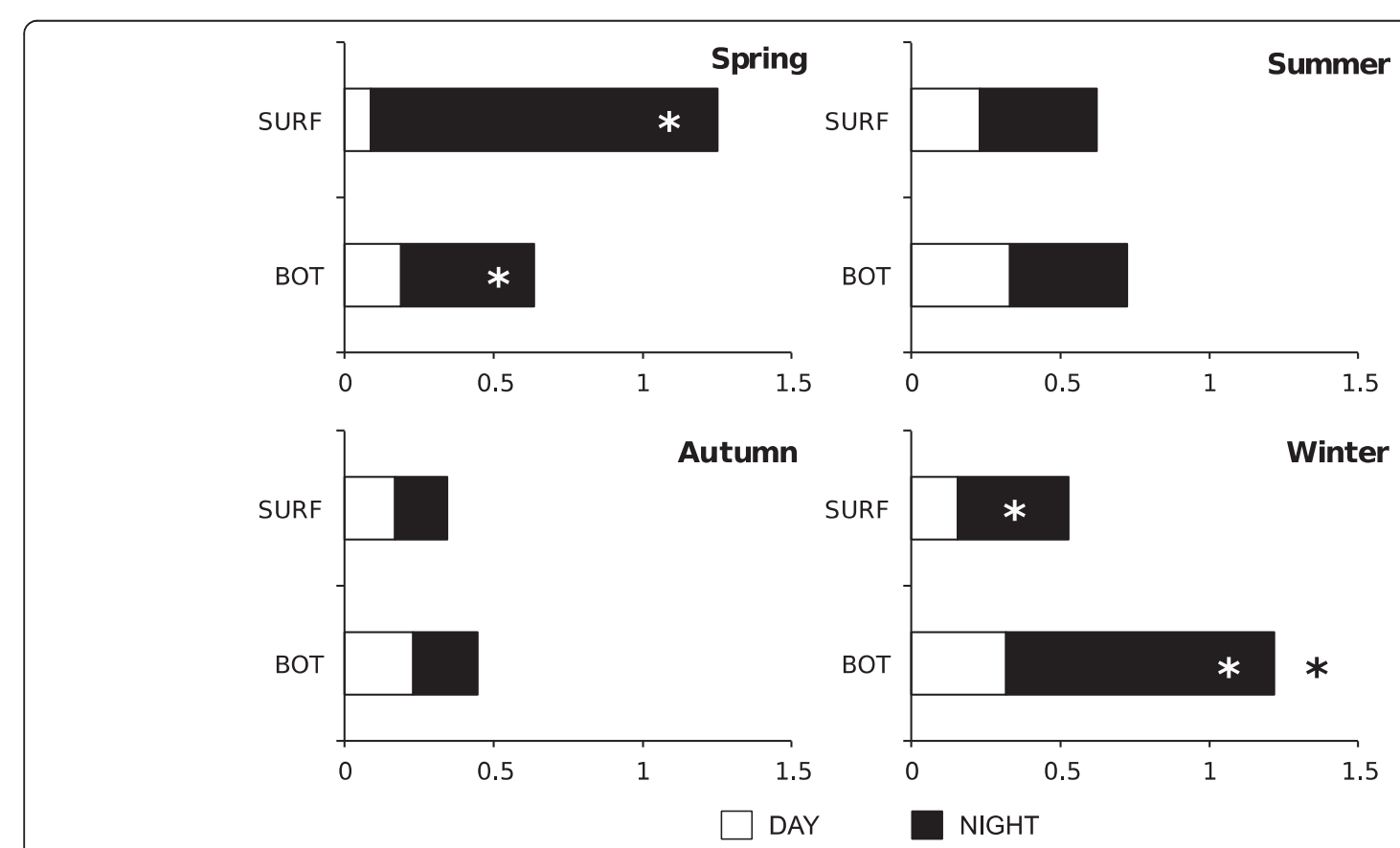

Fig. 5 Diel vertical distribution of Copepoda biomass $\left(\mathrm{mg} 100 \mathrm{~m}^{-3}\right.$ ) during the study period in the Mondego estuary. ${ }^{*}$ Significant differences $(p<0.05)$ 

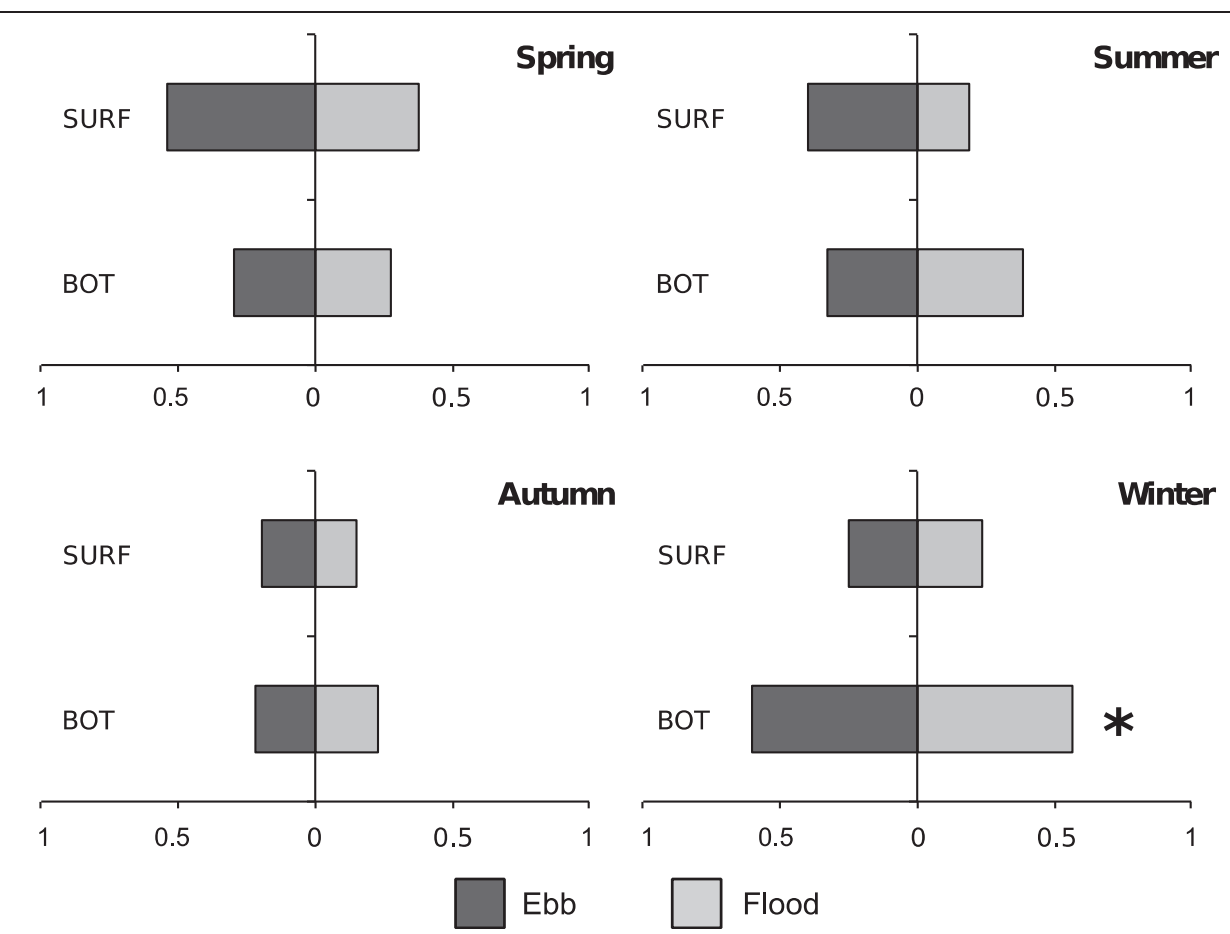

Fig. 6 Tidal vertical distribution of Copepoda biomass $\left(\mathrm{mg} \mathrm{m}^{-3}\right)$ during the study period in the Mondego estuary. ${ }^{*}$ Significant differences $(p<0.05)$

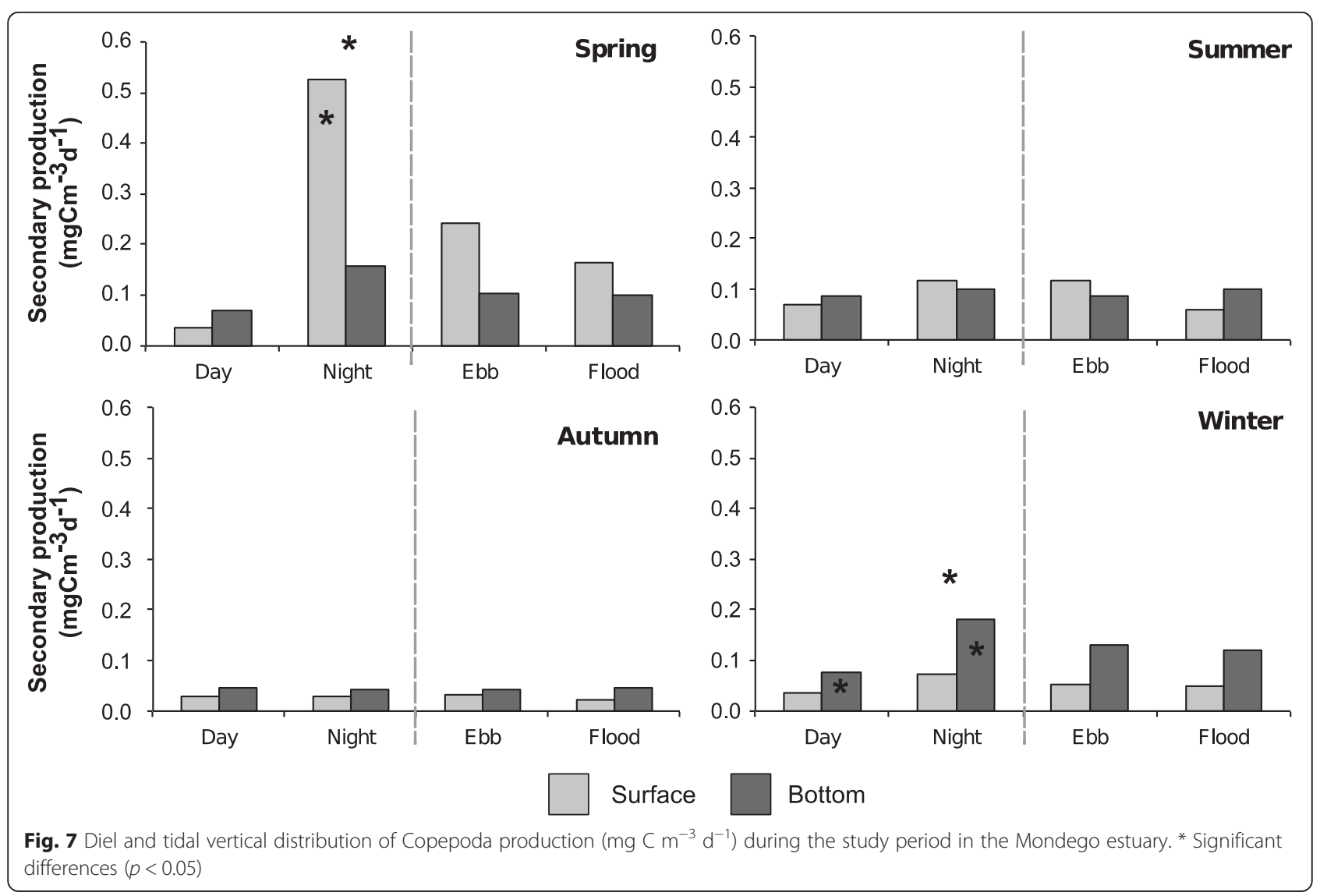


Table 1 Season GLM results

\begin{tabular}{lllll}
\hline & Spring & Summer & Autumn & Winter \\
\hline Salinity & & & & \\
Temperature & & $(-)$ & $(-)$ & \\
Chlorophyll $a$ & & $*$ & $*$ & \\
SPM & & & $(-)$ & \\
Diel & $*$ & & & \\
Tide & & & & $*$ \\
Depth & $*$ & & & \\
Diel:depth & $*$ & & & \\
Tide:depth & & & & \\
F-statistic & 5.786 & 3.287 & 0.319 & 5.418 \\
$p$ value & 0.002 & 0.080 & 0.006 & 0.008 \\
$R^{2}$ & 0.29 & 0.09 & 0.18 & 0.21 \\
\hline
\end{tabular}

SPM suspended particulate matter

*Significant $(p<0.05)$ environmental variables

(-) Excluded variables due to collinearity

determination, explaining around 29 and $21 \%$ of the data variations (Table 1 ).

During spring and winter, diel phase and depth influenced copepod secondary production, and thus, data were presented according to day/night periods and bottom/surface depth (Fig. 7). For spring, copepod secondary production displayed lower values during the day. Furthermore, night values showed higher variability. Also, vertical distribution seemed to vary according to diel phase: higher production in bottom samples during the day and in surface samples during the night (Fig. 7).

In the winter, copepod production was also higher during the night, both in surface and bottom samples. Additionally, copepod secondary production was generally higher in bottom samples, both during the day and night (Fig. 7). The highest variation in copepod production was observed at night in bottom samples.

The GLM analysis pointed out $\mathrm{Chl}$ a as the best predictor for secondary production during summer and autumn; however, the relationship varied according with the season. During summer, higher $\mathrm{Chl}$ a resulted in lower secondary production (negative relationship) while in autumn; increased secondary production was observed with higher $\mathrm{Chl}$ a (positive relationship) (Fig. 8).

\section{Discussion}

Zooplankton is composed of animals from several taxonomic groups, but crustaceans are generally dominant. In terms of the overall contribution to zooplankton biomass, the most important group found during this study was Copepoda. This is in accordance with previous studies of the zooplankton community in the Mondego estuary (Marques et al. 2006). In fact, total zooplankton biomass reflected the seasonal variation of the copepod population quite well. The results are also parallel to findings in other geographical areas, which revealed that copepods usually contribute with the majority of zooplankton biomass and species diversity in estuaries (Arashkevich et al. 2002, Leandro et al. 2007, Uye and Liang 1998). Other organisms encountered included gelatinous species (consisting primarily of medusae, chaetognaths, and appendicularians). Due to low dry weight, their contribution to biomass was minimal. Nevertheless, their total predatory impact on the zooplankton community is possibly important since these carnivores have high grazing rates (Marshalonis and Pinckney 2008, Purcell et al. 1994). When numerous, they significantly affect plankton species occurrence and size composition.

Although estuarine ecosystems are generally characterized by high zooplanktonic biomass and secondary production values (David et al. 2006), the results obtained for the Mondego estuary are lower than those encountered in the literature for other regions, such as the Ria de Aveiro in Portugal (Leandro et al. 2007), Westerschelde in the Netherlands (Escaravage and Soetaert 1995), Kattegat in Denmark (Kiørboe and Nielsen 1994), and the Inland Sea of Japan (Uye and Liang 1998). These authors found numbers ranging from a minimum of $1.18 \mathrm{mg} \mathrm{C} \mathrm{m}^{-3} \mathrm{~d}$ ${ }^{-1}$ (Kattegat) to a maximum of $6.85 \mathrm{mg} \mathrm{C} \mathrm{m}^{-3} \mathrm{~d}^{-1}$ (Inland Sea of Japan) (Table 2). Maximum production for the Mondego estuary was only $0.125 \mathrm{mg} \mathrm{C} \mathrm{m}^{-3} \mathrm{~d}^{-1}$ when considering the contribution of copepods alone (main taxonomic group).

Methods for zooplankton biomass estimation are relatively standard and calculated values have been reported for different areas worldwide (Fernández de Puelles et al. 2003, Hays et al. 2001, Irigoien and Castel 1995, Kimmerer and McKinnon 1987, Melo Júnior et al. 2007, Rawlinson et al. 2005, Roman et al. 2002). However, data are generally obtained from samples collected with nets of mesh diameter ranging from 64 to $300 \mu \mathrm{m}$. It is important to note that net selectivity could have a significant influence on the generated data since it can differentially represent the dominant species and/or the proportion of developmental stages present in the environment. Most coastal mesozooplankton assemblages are composed of small-sized organisms, as well as early developmental stages of larger species, which generally dominate in terms of abundance and biomass (Turner 2004). Consequently, the differences observed in this study were probably due to the higher mesh size used in comparison to other studies 64 and $125 \mu \mathrm{m}$-Ria de Aveiro, $55 \mu \mathrm{m}$-Westerschelde, $50 \mu \mathrm{m}$-Kattegat and $62 \mu \mathrm{m}$-Inland Sea of Japan). Due to their small body size, microzooplankton, particularly ciliated protozoans, have higher weight-specific physiological rates such as feeding, respiration, excretion, and growth than large 


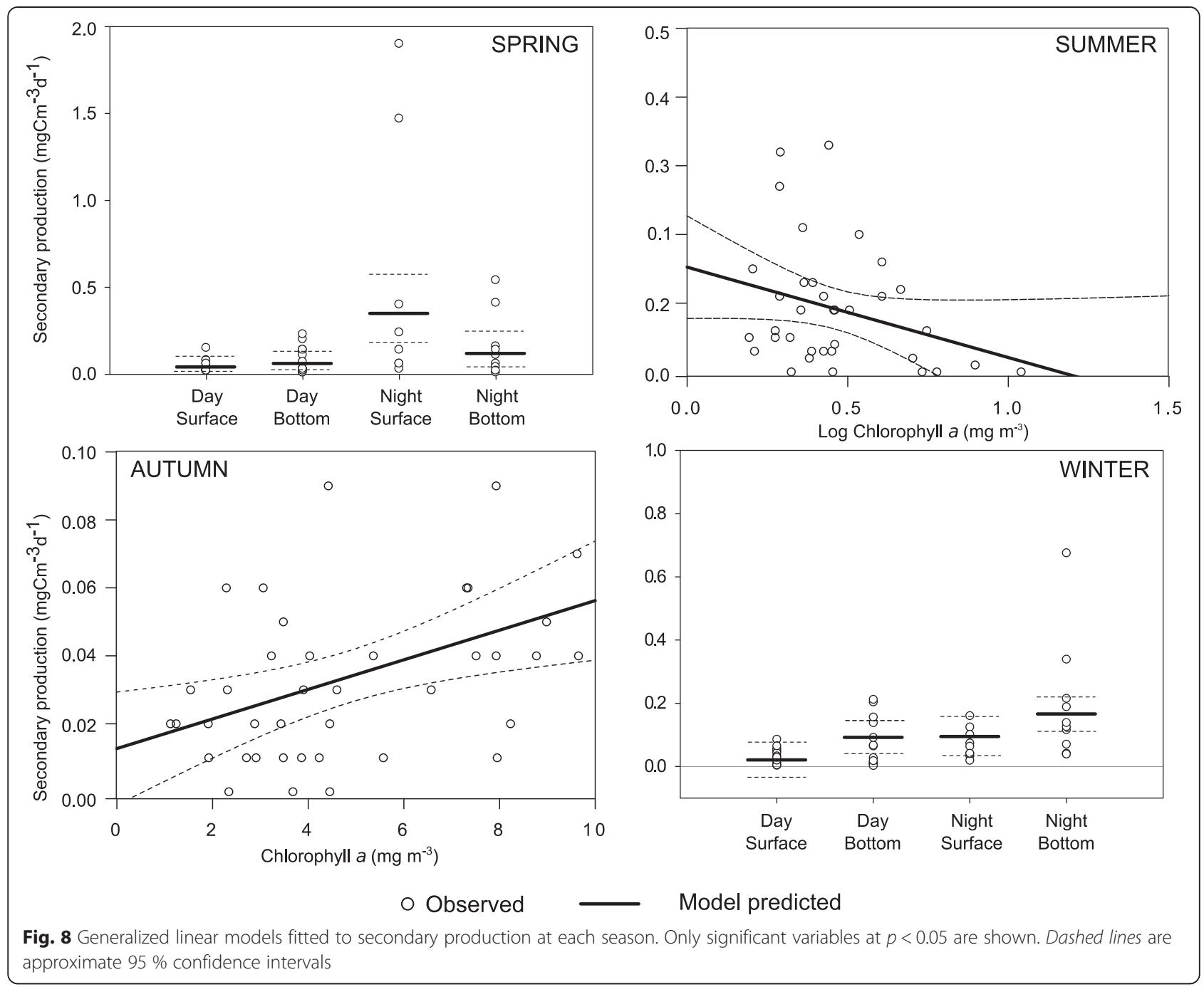

metazoans. Therefore, the frequent undersampling of small copepod species may lead to a limited view of the planktonic systems and must be considered when comparing results. In this respect, the importance of small copepods is well recognized as a fundamental link in marine food webs, serving as major grazers of phytoplankton and prey for ichthyoplankton and other larger pelagic carnivores (Turner 2004, Verity et al. 2002). While it is now recognized that many factors contribute to fish recruitment
(Houde 2008), the amount of zooplankton prey available to larval fish remains without a doubt vital.

Concerning the estimation of secondary production rate, the current lack of a completely accepted method for its determination is a consequence of the variety of factors affecting secondary production, being difficult to determine the efficacy of each one. Moreover, in pelagic research, efforts on zooplankton growth rates are mainly focused on copepods (Hirst and McKinnon 2001) and

Table 2 Daily secondary production values encountered in different coastal regions for zooplankton

\begin{tabular}{llll}
\hline Location & Production $\left(\mathrm{mg} \mathrm{C} \mathrm{m}^{-3} \mathrm{~d}^{-1}\right)$ & Empirical model or method & Reference \\
\hline Kattegat, Denmark & 1.2 & Weight-specific egg production rates & Kiørboe and Nielsen 1994 \\
Westerschelde, Netherlands & 1.9 & Growth rates (temperature-dependent growth model) & Escaravage and Soetaert 1995 \\
Inland Sea of Japan & 6.9 & Length-weight relationships, instantaneous growth rates & Uye and Liang 1998 \\
Ria de Aveiro, Portugal & 3.7 & Huntley and Lopez (1992) & Leandro et al. 2007 \\
& 2.9 & Hirst and Bunker (2003) & Present study \\
\hline
\end{tabular}


not on communities of different species. As mentioned earlier, several methods can be used to determine secondary production for zooplankton, but in addition to biomass values, all of them require the determination of growth rates (Leandro et al. 2007), which cannot always be done directly. Due to the nature of the preserved samples in this study, available field parameters, and the lack of more detailed information, it was decided that the mathematical growth model described by Huntley and Lopez (1992) would be the most appropriate one to conduct the intended analysis. However, this model depends only on temperature to make predictions and does not assume that copepod/zooplankton growth may be limited by food at some points during the year (Burkill and Kendall 1982, Peterson et al. 1991). Its general nature does not take into account particular characteristics of the ecosystem either. Hence, caution must be used in its application, as it tends to overestimate growth rates (Kleppel et al. 1996). Despite this, it is important to understand that this type of model can be a reliable tool for estimating secondary production because it considers the ecologically relevant parameters of biomass and growth rates, which have been extensively studied.

During the study period, both copepod biomass and production rate displayed a weak seasonal effect. This lack of cyclic variation may be related to species replacement when they are seasonally substituted by each other yet maintaining average biomass (e.g., freshwater species replaced by marine ones). Changes in copepod production were only detected in autumn, which had the lowest values. During autumn, the increased prevalence of predators (e.g., mysids and chaetognaths) most likely influenced copepod community structure by favoring species with lower growth rates. Salinity values detected at the surface during this season indicated a strong input of freshwater that may also affect the planktonic community. According to Kimmerer (2002), variations on estuarine organisms' abundance and survival may occur through attributes of physical habitat that vary with river flow, and negative responses can be expected mainly from marine species due to the seaward displacement of their habitat, and therefore, population centers.

During autumn, the low production rates were positively related with chlorophyll a, showing no diel, tidal or vertical patterns. The same occurred during summer, although presenting an inverse (negative) relationship with primary productivity. These results further suggest a seasonal shift in the copepods' diet in the estuary. Contrasting with autumn, which exhibited high values of chlorophyll a, the amount of primary production in summer in the Mondego estuary was quite certainly well below the carbon requirements of the copepod population, not being sufficient enough to cover their nutritional needs. Phytoplankton appears to be the most important carbon source over the course of autumn, while in summer, alternative sources are utilized. Many researchers have noted the paradox between high copepod biomass in estuarine areas with a large quantity of particles and low phytoplankton production (David et al. 2006). This suggests the possible use of detritus (essentially originating from terrestrial plants) as a food source for estuarine copepods. For instance, Diodato and Hoffmeyer (2008) found that Acartia tonsa, the most abundant species in the Mondego estuary, consumed detritus in the Bahía Blanca Estuary (Argentina), and a study of the cycling of organic material in the Kariega Estuary (South Africa) revealed that mesozooplankton used both phytoplankton and detritus as food (Richoux and Froneman 2008).

In spring and winter, GLM analysis identified diel and vertical patterns as having a key role on production rate variations, as opposed to summer and autumn. In fact, during spring and winter, both biomass and production rates were significantly higher at nighttime than at daylight hours. Additionally, spring copepod production rates seem to show a vertical variation associated with depth (changes in depth according to diel phase); a strong evidence of diel vertical migrations. It is generally accepted that the daily sunlight cycle plays an important role in the diel vertical migration (DVM) behavior of zooplankton, which has been observed in coastal regions (e.g., Zhu et al. 2000, Devreker et al. 2008, Marques et al. 2009, Primo et al. 2012). Nocturnal vertical movements in the water column have commonly been reported for different taxa, including copepods (Rawlinson et al. 2005). Synergistic benefits might have shaped the evolution of this adaptive complex behavior in response to variations in the environment. Explanations for the vertical migration mechanism include environmental factors (e.g., light, temperature, salinity, oxygen, and diet), predator-avoidance, and energy and resource utilization (for a detailed review see Hays 2003). This behavior causes active transport of dissolved organic and inorganic carbon and nitrogen and plays a welldocumented role in biogeochemical cycling (Steinberg et al. 2012). Furthermore, there are associated consequences for higher trophic levels of this behavior. For example, Hays (2003) noted that some predators at higher trophic levels modify their activity to exploit the vertical movement of the food source. The food chain of the Mondego estuary supports an important fish community (Martinho et al. 2007). Studies performed by Martinho et al. (2008) and Dolbeth et al. (2008), who analyzed the feeding ecology of the main fish community, concluded that copepods were an important component of the fish diet. As a result, DVM behavior could lead to important trophodynamic effects in the fish community. 
Vertical patterns were stronger during winter, when bottom samples showed increased biomass and production rates compared to surface samples. Despite autumn samples presenting higher salinity stratification, during the winter, salinity at the surface in the Mondego estuary is highly variable due to changes in freshwater flow (Marques et al. 2009). The instability of the water column influences planktonic organisms to gather near the bottom in order to avoid being flushed out of the estuary. Contrary to diel and vertical distributions, variations in biomass and secondary production showed no relation with tides. This can indicate that the amount of organisms imported (flood) was equivalent to those exported (ebb) from the estuary. However, results from vertical salinity variation pointed out low stratification during spring and summer. At this time a persistent landward current seemed to occur, increasing the import of biomass and transportation to upstream areas. The higher freshwater flow detected in autumn and its strong associated advective effects (export) are mainly seen at the surface, but the same amount of biomass and production rate appear to be inputted near the bottom, hence, the absence of vertical differences. During the winter, copepods tend to agglomerate close to the bottom, which results in a lower transport of organisms.

\section{Conclusions}

Of the eight taxonomic groups identified, Copepoda, Mysidacea, and Cladocera were the most significant. Copepods represented a large percentage of the total biomass, but production calculated with the Huntley and Lopez (1992) model was lower than expected, possibly due to the large mesh size used $(335 \mu \mathrm{m})$. Production rates revealed the influence of diel vertical patterns, with higher values being registered in depth at nocturnal periods. The Mondego estuary did not display the typical seasonal patterns of high zooplankton biomass in summer and low in winter, common to similar sites (Fernández de Puelles et al. 2003, Rawlinson et al. 2005). Nonetheless, in the western Mediterranean basin, the range of zooplankton biomass and occurrence is not always well defined, and comparisons between data of other systems should be done carefully due to the great variety of sampling methods. Tidal exchange also revealed a non-significant variation, with little difference between imported and exported biomass and production. This is not uncommon, and studies in other locations have yielded equivocal results with different explanations, as discussed by Melo Júnior et al. (2007). In a shallow coastal ecosystem like the Mondego estuary, the influence of river discharge and varying salinity levels are significant, and it is possible to conclude that local factors such as freshwater flow, predation, and food limitation may regulate the seasonal variations in biomass and production. This study represents the first attempt at estimating biomass and secondary production of the zooplankton community of the Mondego estuary. It would be important to conduct future studies with smaller mesh size nets in order to estimate the contribution of smaller sized zooplankton, as well as to define a copepod growth model specific to this ecosystem for achieving more accurate production estimates.

\section{Competing interests}

The authors declare that they have no competing interests.

\section{Authors' contributions}

SCM, FM, and MAP collected the data and helped draft the manuscript. DAG was responsible for the laboratory procedures and prepared the manuscript. MDB helped in the lab work. ALP performed the statistical analyses and helped draft the manuscript. All authors read and approved the final manuscript.

\section{Acknowledgements}

The present work was supported by the FCT (Portuguese Foundation for Science and Technology) through the COMPARE Project (PTDC/MAR/121788/ 2010) financed by the POPH (Portuguese Operational Human Potential Program), QREN Portugal (Portuguese National Strategic Reference Framework), and MCTES (Portuguese Ministry of Science, Technology, and Higher Education), through postdoctoral grants attributed to SCM (SFRH/ $\mathrm{BPD} / 65541 / 2009)$ and ALP (SFRH/BPD/91030/2012) and through the Investigador FCT program to F Martinho (IF/01410/2012). The authors are especially indebted to Prof. Ulisses M. Azeiteiro and Dr. Ivan Viegas, who were involved in fieldwork.

\section{Author details}

'Department of Life Sciences, Centre for Functional Ecology-CFE, University of Coimbra, Calçada Martins de Freitas, Coimbra 3000-456, Portugal. ${ }^{2}$ Department of Biology and CESAM, University of Aveiro, Campus Universitário de Santiago, Aveiro 3810-193, Portugal.

Received: 14 November 2014 Accepted: 7 August 2015

Published online: 11 August 2015

\section{References}

Akaike H (1974) A new look at the statistical model identification. IEEE Trans Automat Contr 19(6):716-723

American Public Health Association (APHA) (1995) Standard methods for the examination of water and wastewater, 19th edn. American Public Health Association, Washington, D.C., p 43

Anderson MJ, Gorley RN, Clarke RK (2008) PERMANOVA+ for PRIMER: guide to software and statistical methods. PRIMER-E Ltd, Plymouth, UK, p 214

Arashkevich E, Wassmannb P, Pasternaka A, Riserb CW (2002) Seasonal and spatial changes in biomass, structure, and development progress of the Zooplankton community in the Barents Sea. J Marine Sys 38:125-145

Azeiteiro UM, Marques JC, Ré P (1999) Zooplankton annual cycle in the Mondego river estuary (Portugal). Arquivos Museu Bocage 3(8):239-263

Båmstedt U (1986) Chemical composition and energy content. In: Corner EDS, OHara SCM (eds) The biological chemistry of marine copepods. Clarendon Press, Oxford, pp 1-58

Beaugrand G, Brander KM, Lindley JA, Souissi S, Reid PC (2003) Plankton effect on cod recruitment in the North Sea. Nature 426:661-664

Burkill PH, Kendall TF (1982) Production of the copepod Eurytemora affinis in the Bristol Channel. Mar Ecol Prog Ser 7:21-31

Conover RJ, Wilson S, Harding GCH, Vass P (1995) Climate, copepods and cod: some thoughts on the long-range prospects for a sustainable northern cod fishery. Clim Res 5:69-82

David V, Sautour B, Galois R, Chardy P (2006) The paradox high zooplankton biomass-low vegetal particulate organic matter in high turbidity zones: what way for energy transfer? J Exp Mar Biol Ecol 333:202-218

Day JW, Hall CAS, Kemp WM, Yanez-Arancib A (1989) Estuarine ecology. John Wiley and Sons, New York, p 558 
de Melo Júnior M, Paranaguá MN, Schwamborn R, Leitão SM, Ekau W (2007) Fluxes of zooplankton biomass between a tidal estuary and the sea in Northeastern Brazil. Brazilian J Oceanogr 55(4):239-249

Devreker D, Souissi S, Molinero JC (2008) High frequency Eulerian sampling of the population of the calanoid copepod Eurytemora affinis in the Seine estuary: role of the tidal regime. J Plankton Res 30:1329-1342

Diodato SL, Hoffmeyer MS (2008) Contribution of planktonic and detritic fractions to the natural diet of mesozooplankton in Bahía Blanca Estuary. Hydrobiologia 614:83-90

Dolbeth M, Martinho F, Leitão R, Cabral H, Pardal MA (2008) Feeding patterns of the dominant benthic and demersal fish community in a temperate estuary. J FISH BIOL 72(10):2500-2517

Elliott M, McLusky DS (2002) The need for definitions in understanding estuaries. Estuar Coast Shelf S 55:815-827

Escaravage V, Soetaert K (1995) Secondary production of the brackish copepod communities and their contribution to the carbon fluxes in the Westerschelde estuary (The Netherlands ). Hydrobiologia 311:103-114

Fernández de Puelles ML, Grás D, Hernández-León S (2003) Annual cycle of zooplankton biomass, abundance and species composition in the neritic area of the Balearic Sea, Western Mediterranean. Mar Ecol 24:123-139

Hays GC (2003) A review of the adaptive significance and ecosystem consequences of zooplankton diel vertical migrations. Hydrobiologia 503:163-170

Hays GC, Harris RP, Head RN (2001) Diel changes in the near-surface biomass of zooplankton and the carbon content of vertical migrants. Deep Res Part II Top Stud Oceanogr 48:1063-1068

Hirst A, McKinnon A (2001) Does egg production represent adult female copepod growth? A call to account for body weight changes. Mar Ecol-Prog Ser 223:179-199

Hirst AG, Bunker AJ (2003) Growth of marine planktonic copepods: Global rates and patterns in relation to chlorophyll a, temperature, and body weight. Limnol Oceanogr 48(5):1988-2010

Houde ED (2008) Emerging from Hjort's Shadow. J Northwest Atl Fish Sci 41:53-70

Huntley ME, Lopez MD (1992) Temperature-dependent production of marine copepods: a global synthesis. Am Nat 140:201-242

Irigoien X, Castel J (1995) Feeding rates and productivity of the copepod Acartia bifilosa in a highly turbid estuary; the Gironde (SW France). Hydrobiologia 311:115-125

Kimmerer, WJ (2002) Effects of freshwater flow on abundance of estuarine organisms: physical effects or trophic linkages? Mar Ecol-Prog Ser 243:39-55.

Kimmerer WJ (1987) The theory of secondary production calculations for continuously reproducing populations. Limnol Oceanogr 32:1-13

Kimmerer WJ, Mckinnon AD (1987) Growth, mortality, and secondary production of the copepod Acartia tranteri in Westernport Bay, Australia. Limnol Oceanogr 32:14-28

Kiørboe T, Nielsen TG (1994) Regulation of zooplankton biomass and production in a temperate, coastal ecosystem. 1. Copepods. Limnol Oceanogr 39:493-507

Kleppel GS (1992) Environmental regulation of feeding and egg production by Acartia tonsa of Southern California. Mar Biol 112:57-65

Kleppel GS, Davis CS, Carter K (1996) Temperature and copepod growth in the sea: a comment on the temperature-dependent model of Huntley and Lopez. Am Nat 148:397-406

Leandro S, Morgado F, Pereira F, Queiroga H (2007) Temporal changes of abundance, biomass and production of copepod community in a shallow temperate estuary (Ria de Aveiro, Portugal). Estuar Coast Shelf Sci 74:215-222

Leandro SM, Tiselius P, Marques SC, Avelelas F, Correia C, Sa P, Queiroga H (2014) Copepod production estimated by combining in situ data and specific temperature-dependent somatic growth models. Hydrobiologia DOl:. doi:10.1007/s10750-014-1833-5

Lovegrove T (1962) The effect of various factors on dry weight values. In: Rapports et procès-verbaux des réunions du Conseil Permanent International pour l'Exploration de la Mer, vol 153., pp 86-91

Lovegrove T (1966) The determination of dry weight of plankton and the effect of various factors on the values obtained. In: Barnes $\mathrm{H}$ (ed) Some contemporary studies in marine science. George Allen and Unwin, London, pp 462-467

Marques JC, Graça MA, Pardal MA (2002) Introducing the Mondego river basin. In: Pardal MA, Marques JC, Graça MA (eds) Aquatic ecology of the mondego river basin - global importance of local experience. Imprensa da Universidade de Coimbra, Coimbra, pp 7-12

Marques S, Azeiteiro U, Martinho F, Viegas I, Pardal MÂ (2009) Evaluation of estuarine mesozooplankton dynamics at a fine temporal scale: the role of seasonal, lunar and diel cycles. J of Plankton Res 10: 1249-1263.
Marques SC, Azeiteiro UM, Marques JC, Neto JM, Pardal MA (2006) Zooplankton and ichthyoplankton communities in a temperate estuary: spatial and temporal patterns. J Plankton Res 28:297-312

Marques SC, Pardal MA, Pereira MJ, Gonçalves F, Marques JC, Azeiteiro UM (2007) Zooplankton distribution and dynamics in a temperate shallow estuary. Hydrobiologia 587:213-223

Marques SC, Primo AL, Martinho F, Azeiteiro UM, Pardal MA (2014) Shifts in estuarine zooplankton variability following extreme climate events: a comparison between drought and regular years. Mar Ecol-Prog Ser 499:65-76

Marshalonis D, Pinckney JL (2008) Grazing and assimilation rate estimates of hydromedusae from a temperate tidal creek system. Hydrobiologia 606:203-211

Martinho F, Leitão R, Viegas I, Dolbeth M, Neto JM, Cabral HN, Pardal MA (2007) The influence of an extreme drought event in the fish community of a southern Europe temperate estuary. Estuar Coast Shelf Sci 75:537-546

Martinho F, Leitão R, Neto JM, Cabral H (2008) Estuarine colonization, population structure and nursery functioning for 0-group sea bass (Dicentrarchus labrax), flounder (Platichthys flesus) and sole (Solea solea) in a mesotidal temperate estuary. J Appl Ichthyol 24:229-237

McLusky DS, Elliott M (2004) The estuarine ecosystem: ecology, threats, and management. Oxford University Press, Oxford, p 214

Omori M, Ikeda T (1984) Methods in marine zooplankton ecology. John Wiley and Sons, New York, p 332

Parsons TR, Maita Y, Lally CM (1985) Pigments. In: A manual of chemical and biological methods for seawater analysis. Pergamon Press, Oxford, pp 101-104

Peterson WT, Kiørboe P, Tiselius T (1991) Copepod egg production, moulting and growth rates, and secondary production, in the Skagerrak in August 1988. J Plankton Res 13:131-154

Primo AL, Azeiteiro UM, Marques SC, Martinho F, Pardal MA (2009) Changes in zooplankton diversity and distribution pattern under varying precipitation regimes in a southern temperate estuary. Estuar Coast Shelf Sci 82:341-347

Primo AL, Azeiteiro UM, Marques SC, Ré P, Pardal MA (2012) Vertical patterns of ichthyoplankton at the interface between a temperate estuary and adjacent coastal waters: seasonal relation to diel and tidal cycles. J Mar Syst 95:16-23

Purcell JE, White JR, Roman MR (1994) Predation by gelatinous zooplankton and resource limitation potential controls of Acartia tonsa copepod populations in Chesapeake Bay. Limnol Oceanogr 39:263-278

R Development Core Team (2008). R: A language and environment for statistical computing. R Foundation for Statistical Computing, Vienna, Austria. ISBN 3900051-07-0, URL http://www.Rproject.org.

Rawlinson K, Davenport J, Barnes D (2005) Tidal exchange of zooplankton between Lough Hyne and the adjacent coast. Estuar Coast Shelf Sci 62:205-215

Ré P, Azeiteiro U, Morgado F (2005) Ecologia do Plâncton Marinho e Estuarino. Edições Afrontamento, Porto, p 140

Richardson AJ (2008) In hot water: zooplankton and climate change. ICES J Mar Sci 65:279-295

Richoux NB, Froneman PW (2008) Trophic ecology of dominant zooplankton and macrofauna in a temperate, oligotrophic South African estuary: a fatty acid approach. Mar Ecol Prog Ser 357:121-137

Roman MR, Adolf HA, Landry MR, Madin LP (2002) Estimates of oceanic mesozooplankton production: a comparison using the Bermuda and Hawaii time-series data. Deep Res 49:175-192

Runge JA, Roff JC (2000) The measurement of growth and reproductive rates. In: Harris RP, Wiebe PH, Lenz J, Skjoldal HR, Huntley M (eds) ICES zooplankton methodology manual. Academic Press, London, pp 401-454

Steinberg DK, Lomas MW, Cope JS (2012) Long-term increase in mesozooplankton biomass in the Sargasso Sea: Linkage to climate and implications for food web dynamics and biogeochemical cycling. Glob. Biogeochem. Cycles 26.

Turner JT (2004) The importance of small planktonic copepods and their roles in pelagic marine food webs. Zool Stud 43:255-266

Uye S, Liang D (1998) Copepods attain high abundance, biomass and production in the absence of large predators but suffer cannibalistic loss. J Marine Syst 15:495-501

Verity PG, Wassmann P, Frisher ME, Howard-Jones MH, Allen AE (2002) Grazing of primary production by microzooplankton in the Barents Sea during early summer. J Mar Syst 38:125-145

Vieira L, Morgado F, Ré P, Nogueira A, Pastorinho R, Pereira M, Bacelar-Nicolau P, Marques JC, Azeiteiro UM (2003) Population dynamics of Acartia clausi from a temperate estuary (Mondego estuary, Western Portugal). Invertebr Reprod Dev 44:9-15

Zhu X-H, Takasugi Y, Nagao M, Hashimoto E (2000) Diurnal cycle of sound scatterers and measurements of turbidity using ADCP in Beppu Bay. J Oceanogr 56:559-565 